\title{
The Influence of Health Promotion Media With Bimanesse Local Language on Parents and Their Families Understanding about Characteristic of Drug User
}

\author{
Ade Wulandari, Sukmawati, Martiningsih
}

Nursing Study Program in Bima, Health Polytechnic Ministry of Health Mataram, Street of Gatot Soebroto, Bima City, Nusa Tenggara Barat, Indonesia

Email : adewulandari0401@gmail.com

\begin{abstract}
Background: The consumption of narcotics, psychotropic and addictive substances areincreased among teenagers in Bima. Efforts to prevent and suppress drug trafficking and their abuse need to be implemented continuously through the process of education and information sharing among families whohas teenagers. The use of local wisdom in health promotion can be done by using media with local language. Purpose: This study aims to determine the effect of delivering information about the characteristics of drug users using the local Bima Language booklet towards family knowledge. Methods: This study was conducted by using post test only design that use control group with 30 respondents for each group. The data was obtained by observation and interview. The data analysis used a Nonparametric Test with the Mann-Whitney test. Results: The results showed that there was no difference in understanding between respondents who read booklets in local Bima language and respondents who read booklets in Indonesian language with $p=0.058$. Conclusion: The use of the Booklet in local Bima language has the same effect as the use of booklets in Indonesian language.
\end{abstract}

Keyword: adolescence, family, health promotion, local language, media, drugs

\section{INTRODUCTION}

The rise of drug abuse is now becoming an issue that needs attention. West Nusa Tenggara Province (NTB) is considered as one of the areas with a drug emergency status in line with an increase in drug abuse. In 2014, drug abusers in NTB were predicted to reach 51,519 people from the total population reaching $3,423,300$ people or 1.50 percent was drug users. The increase in drug users and abusers commonly occured among the younger generation, especially teenagers and children (Antaranews, 2015).

Based on data from the National Narcotics Agency (BNN) it is known that there is a tendency to increase in the number of drug users in the age group of 16-19 years, namely in 2010 as many as 1,515 and in 2012 to 2,106 (Pusat Data dan Informasi Kemeterian Kesehatan RI, 2014). Particularly in Kabupaten and Kota Bima, drug abuse continues to increase from year to year. Evidenced by the data held by the Bima District Court (PN) which shows an increase in the percentage of drug cases from criminal cases handled. In 2014 there were 10.91\% of drug cases from 394 criminal cases handled. This percentage increased to $11.42 \%$ in 2015 and as of 31 August 2016 the percentage increased to $12.11 \%$ (SUARANTB.com, 2016).

The increase in drug users and abusers commonly occured among the younger generation, especially teenagers and children (Antaranews, 2015). A study of drug abuse among adolescents in Peshwar Pakistan showed that of the 61 respondents involved in the study, $89 \%$ of respondents began to be involved in drug abuse at the age range of 12 to 21 years. Heroin type drugs are usually the first choice for drug use when they start to become users (Nasir, Khan and Tabassum, 2015). Other research also supports the findings in a study conducted by Nasir et al where substance abuse often begins as a teenager (Schulte PhD and Hser PhD, 2014). This can be attributed to the stage 
of biological and social development of adolescents where teenagers tend to try new experiences such as trying to use narcotics and illegal drugs and alcohol (Schulte PhD and Hser PhD, 2014).

The impact of increasing substance abuse, especially the drug type namely Tramadol in the City and District of Bima has caused at least 405 teenagers from the City of Bima to be administered to the NTB Provincial Mental Hospital because they were detected to have neurological disorders (SUARANTB.com, 2016). Case study conducted on secondary school students in the City of Bima shows a number of negative effects of drug abuse on the physical, psychological, social and spiritual aspects of the subject under study. Physically, the subject had experience difficulty in breathing, headaches, body temperature had been increase at any time and difficult for sleeping. On the psychological aspect, the subject became lazy, slow, often tense and agitated, difficult to focus, emotionally unstable and feeling depressed. The subject felt excluded from the social environment and in the spiritual aspect caused the subject to leave the usual worship done (Nurmaya, 2016).

It needs some efforts to improve the role and function of parents in preventing risky behavior in adolescents, parents need to have sufficient knowledge about narcotics and illegal drugs, the ways and the dangers of abuse and how to recognize any characteristics such as physical, emotional and behavior of a person abusing substance abusers. In order to provide knowledge to parents and families, health promotion activities might be an alternative approach. Based on a study, it shows that health promotion activities both in the form of counseling, demonstrations and through print media can elevate one's knowledge at a better level (Rusmiati, Silitonga and Warendi, 2018).

It is important for parents to Share information about health to their teenagers. Parenting through effective communication between parents and children tends to make teenagers do not have risk behaviors (Ungsianik and Yuliati, 2017). Empowerment of parents through increased knowledge is in line with the healthy community movement program for healthy living with a family approach in supporting a healthy Indonesia program. The development of programs to educate parents or families also needs to be implemented that efforts to promote health and prevent risky behavior of substance abuse in adolescents. It can be started from the family level as the closest part of teenage life.

The development of health promotion media using local languages as the language of instruction can be one method to deliver information about the dangers of drug abuse for parents and the community. The booklet that contains the characteristics of drug users, psychotropic drugs and other addictive substances (Napza) in Bimanesse language is a form of media to deliver information about the characteristics of drug users that is designed in the form of illustrated illustrations and use local Bimanesse languages. The use of local language in order to deliver information about the characteristics of drug users is expected to be an approach method for parents and families in order to promote health regarding the prevention of drug abuse, especially among adolescents.

\section{METHODS}

This research is a quasiexperimental study that aims to determine the effect of the use of Bimalanguage media toward the knowledge of parents or family about the characteristics of drug users. The assessment of family knowledge about the characteristics of drug users is carried out after parents have been given information about the characteristics of drug users through a booklet. The development of booklet content has been carried out in two methods of approach, namely booklets written in Indonesian and local Bimanesse languages.

The booklet contains information about the characteristics of drug users that consist of 9 physical characteristics, 7 emotional characteristics and 4 behavioral characteristics so that the number of drug user characteristics contained in the booklet is 20 items. Information in the booklet is presented in the form of illustrations using pictures and the explanation of the pictures that 
is presented in Bahasa Indonesian and local Bimanesse Bima for each booklet.

Booklets were given to two groups of respondents who were divided into respondents reading Indonesian booklets as a control group and respondents reading local Bimanesse language booklets as treatment groups. The selection of respondents was carried out randomly toward families at the stage of family development with adolescents that domiciled in Naru Village and Naru Timur Village, Sape subdistrict of Sape, district of Bima. During the period of study from May to October 2017, data were obtained from 30 families in each group.

Respondents' knowledge about the characteristics of drug users was assessed on the third day after given a booklet to read. The data collection tool used a check list sheet that contains information about the characteristics of drug users based on what is explained in the booklet. Respondents' knowledge about the characteristics of drug users was assessed based on the total score acquired. The conclusion of the score for each drug user characteristic that is able to be retold by the respondent after reading the booklet follows the following conditions: the respondent reiterates the drug user characteristics without looking at the booklet, if the respondent is able to mention the drug user characteristics then given a score of 1 for each item that can be mentioned and a score of 0 for items that cannot be mentioned. In addition to obtaining data on respondents 'scores, interviews were also conducted to explore respondents' opinions about delivering information through booklets.

Data from the total score of respondents was then tested for normality data using the Shapiro Wilk test and it was obtained $p$ value $=0.010$ for the control group, which means that the data distribution is not normal. Based on statistical research problems, namely the numerical comparative analytics of two unpaired groups with abnormal data distribution, then in order to determine the effect of the use of local Bimanesse language booklets on parental knowledge about drug user characteristics, the data were then analyzed using the MannWhitney Nonparametric test.

\section{RESULT AND DISCUSSION}

The data obtained as a result of the study consisted of the characteristics of the respondents, the opinions of the respondents about the delivery of information through the booklet, and the relationship of the type of booklet that was read with the respondents' understanding of the characteristics of drug users.

Respondent's characteristics that obtained consist of age, level of education, economic level, frequency of reading booklets and experience of respondents getting information about the characteristics of drug users from other sources of information. Based on the results of univariate analysis, it is known that the frequency distribution of each respondent's characteristics where in the two groups most of the respondents are in the adult age group, with medium education and low economic level. Based on the frequency of reading the booklet, the majority of respondents in both groups read the booklet only twice.

Table 1. Characteristics of Respondents in the treatment group based on age, education, economic level, frequency of reading the booklet and experience in obtaining prior information

\begin{tabular}{lcc}
\hline \multicolumn{1}{c}{ Characteristics } & Frequency & $\%$ \\
\hline Age & & \\
\hline Early adulthood & 23 & 77 \\
Elderly & 7 & 23 \\
\hline Education & & \\
\hline Elementary & 14 & 46.7 \\
Intermediate & 16 & 53.3 \\
\hline Economic level & & \\
\hline Low & 19 & 63.4 \\
Medium & 11 & 36.6 \\
\hline Frequency of reading & & \\
\hline$</=2$ times & 22 & 73.3 \\
$>2$ times & 8 & 26.7 \\
\hline Experinece getting information & \\
\hline Yes & 22 & 73.3 \\
No & 8 & 26.7 \\
\hline Skor $(\bar{x}=9.77)$ & & \\
\hline$>$ average & 16 & 53.3 \\
$<$ average & 14 & 46.7 \\
\hline Total & 30 & 100 \\
\hline
\end{tabular}

According to experience obtained information about the characteristics of drug users from other sources of information, most of the respondents in the group reading the local Bimanesse language booklet stated that they had 
received the same information from television and from the surrounding environment while the majority of the respondents reading bahasa Indonesia booklets had never received information from other sources. When compared with information delivered through television or based on information obtained directly from anybody, most of the respondents said that the information obtained through this booklet is clearer and more complete, so that respondents wish to persuade other family members to read the booklet.

Table 2. Characteristics of Respondents in the control group based on age, education, economic level, frequency of reading the booklet and experience in obtaining prior information

\begin{tabular}{lcc}
\hline \multicolumn{1}{c}{ Characteristics } & Frequency & $\%$ \\
\hline Age & & \\
\hline Adult & 28 & 93.3 \\
Elderly & 2 & 6.7 \\
\hline Total & 30 & 100 \\
\hline Education & 5 & \\
\hline Elementary & 25 & 83.7 \\
Intermediate & 30 & 100 \\
\hline Total & & \\
\hline Economic level & 21 & 70.0 \\
\hline Low & 9 & 30.0 \\
Medium & 30 & 100 \\
\hline Total & 18 \\
\hline \multicolumn{2}{c}{ Frequency of reading } \\
\hline > 2 times & 12 & 60 \\
\hline Total & 30 \\
\hline Experience getting information \\
\hline Yes & 13 \\
No & 17 & 100 \\
\hline Total & 30 & 43.3 \\
\hline Skor $(\bar{x}=8.73)$ & 100 \\
\hline$>$ average & 10 & \\
$<$ average & 20 & 66.7 \\
\hline Total & 30 \\
\hline
\end{tabular}

The results of interviews with respondents' opinions regarding the delivery of information about the characteristics of drug users through booklets revealed that most respondents in both groups said that it was good and attractive. The majority of respondents in the group reading the local Bimanesse language booklet also stated that the booklet in local Bimanesse language version was easier to understand because the delivery of information using local languages that was considered as an innovative and interesting. In addition, the visualisation of the booklet supported by some illustrative images as an explanation makes the booklet more interesting to read. Thus, in general respondents gave a positive response to the media of information in the form of booklets using the local Bimanesse language version.

Table 3. Respondent's opinion about educative delivering using local Bimanesse language

\begin{tabular}{lcc}
\hline $\begin{array}{c}\text { Respondent's } \\
\text { opinion }\end{array}$ & Frequency & $\%$ \\
\hline Good & 15 & 50 \\
Attractive & 5 & 17 \\
understandable & 10 & 33 \\
\hline Total & $\mathbf{3 0}$ & $\mathbf{1 0 0}$ \\
\hline
\end{tabular}

Table 4. Respondent's opinion about educative delivering using Bahasa Indonesia

\begin{tabular}{lcc}
\hline $\begin{array}{c}\text { Respondent's } \\
\text { opinion }\end{array}$ & Frequency & $\%$ \\
\hline Good & 17 & 57 \\
Attractive & 12 & 40 \\
understandable & 1 & 3 \\
\hline \multicolumn{1}{c}{ Total } & 30 & 100 \\
\hline
\end{tabular}

Table 5. The results of test about the influence of external factors on parental knowledge regarding drug user characteristics

\begin{tabular}{lll}
\hline Variable & $\boldsymbol{Z}$ & $\boldsymbol{P}$ \\
\hline Prior information & -.159 & 0.874 \\
Education & -.625 & 0.532 \\
Frequency of reading & -2.592 & 0.010 \\
Economic level & -.057 & 0.954 \\
Age & -.500 & 0.617 \\
\hline
\end{tabular}

Variables that influence respondents' knowledge scores are the frequency of reading booklets, while the experience of getting prior information, education, economic level and age did not have a significant effect. Booklet is a printed media that utilization is closely related to interest in reading. Based on data about the frequency of reading a booklet, it is known that the majority of respondents in the two groups had read the booklet at least twice. This shows that the educational background of respondents who are mostly at the secondary level can be a supporting factor to the respondents' interest in 
reading. This was also recommended by a study of health promotion for parents and families who have teenagers through school tabloids that should consider the level of reader litersi as a target in the development of a media campaign (Merga and $\mathrm{Hu}, 2016$ ). Findings in other studies also recommend the promotion of prevention of substance abuse by utilizing literacy education media such as booklets to enhance cognitive potential (Scull, Kupersmidt and Erausquin, 2014).

The results of the bivariate statistical analysis through the Mann Withney test to determine the effect of the Bima language booklet on the knowledge of the respondents obtained the value of $p=0.058$. Based on the results of this bivariate test, the alternative hypothesis $(\mathrm{Ha})$ is rejected which means that there is no significant difference between the knowledge of respondents who read the local Bimanesse language booklet and those who read bahasa Indonesia booklets. Thus it can be concluded that there is no effect of health promotion through the local Bimanesse language booklet on family knowledge about the characteristics of drug users. However, even though $\mathrm{Ha}$ was rejected, the statistical test results obtained a value of $p=0.058$ which is highly near to the level of significance of the study with a value of $p=0.050$. Based on univariate analysis, it is known that more respondents reading the local Bimanesse language booklet scored is higher average compared to the scores of respondents reading bahasa Indonesia booklets. The difference of the score was possibly occurred because of differences in the frequency of reading booklets between respondents with one another.

Table 6. The results of the test about the effect of health promotion with the Bima language booklet on the knowledge of parents and families regarding the characteristics of drug users

\begin{tabular}{llll}
\hline Group & Mean rank & $P$ & N \\
\hline Treatment & 33.5 & 0.058 & 30 \\
Control & 27.5 & & 30 \\
\hline
\end{tabular}

The use of different languages in order to deliver the same information does not affect the understanding of respondents. This might be understood because in this study, the respondents who interact using the local Bimanesse language and bahasa Indonesia as the language of instruction so that the information presented in both the local Bimanesse language booklet and the bahasa Indonesia booklet can be understandable for the respondents.

In addition, there is another factor in this study that might influence the acquisition of respondents' scores, namely the frequency of reading booklets $(p=0.010)$. The more often the booklet is read, the respondent will have a better understanding. This becomes contradictory because in the treatment group the acquisition of scores above the average that is higher than in the control group even though the frequency of reading the booklet in the treatment group is $<1=2$ times. However, this contradiction possibly occur because the Bima booklet uses local language which is more often used as a language of instruction in daily life and this allows messages delivered in local languages to be more easily accepted by respondents so that when statistical tests are obtained the results that the understanding of the treatment group scored higher than the control group. In addition, based on experience data from previous information, more respondents in the treatment group were exposed to similar information when compared to respondents in the control group.

The ability of respondents to understand the contents of booklets written in two different languages is measured through the ability of respondents to reiterate information about the characteristics of drug users presented in the booklet after the booklet is read. The results of univariate analysis showed that the average score was higher in the group of respondents reading the local Bimanesse language booklet (average score of 9.77) compared to the group reading bahasa Indonesia booklets (average score of 8.73). Respondents who had a high score (score > average score) were more in the group who read the local Bimanesse language booklet as many as 16 respondents and only 10 
respondents in the group who read the bahasa Indonesia booklet. Obtaining a respondent's score can also be related to the experience of getting the same information from other sources such as television and other media. As the results of research on the use of various media to obtain information, it is known that people, especially teenagers, get information through printed media such as newspapers and magazines, television and internet (Solehati, Rahmat and Eli Kosasih, 2019).

The various serious impacts caused by drug abuse among adolescents require attention and treatment such as the community, individual and even more so at the family level as the closest environment for adolescents. Efforts to prevent and suppress drug abuse have been carried out by the government in various forms of activities. Education and delivery of information through various programs for adolescents has been carried out on a school-based service that includes services in the form of socialization about health and the dangers of drug abuse (Nurmaya, 2016). Although various efforts to prevent substance abuse based on school and academic environment have been widely applied at this time, the number of substance abuse in adolescents still tends to increase from year to year (SUARANTB.com, 2016).

The findings in a study explain that drug abuse behavior in adolescents is a form of response to the fear of failure. The fear of failure causes adolescents to become depressed so as to help themselves get rid of the stress they choose to use drugs. It was further explained that the majority of adolescents involved in drug abuse did not have knowledge of the effects and dangers of drug abuse (Nasir, Khan and Tabassum, 2015). Likewise, with family support, the results of studies on the relationship of adjustment between parents and adolescents suggest that drug abuse prevention interventions should be family-based that can potentially reduce the possibility of substance abuse by Hispanic youth (Unger, Ritt-olson and Baezconde-garbanati, 2009). The same thing is also shown by the results of another study conducted by Ochieng (2014) where parents play a role in shaping adolescent behavior. These roles include providing health promotion messages such as not using illegal drugs and cigarettes and the dangers of consuming excessive alcohol (Bertha, 2014). Therefore, parents who have teenagers must have enough knowledge so that they can explain it to their teenagers.

Various models of drug abuse prevention have now referred to the use of information and communication technology such as preventive programs that are based on websites or online media. The current online program generally developed by referring to the orientation of convenience to be applicable for adolescents where the use of online media-based devices are now widely known by the youth, both developed in the school environment and in the community. Referring to the results of a study conducted by Kozdouh, et al., 2018 that efforts to prevent drug abuse in adolescents must involve various related parties including parents (El Kazdouh et al., 2018). This shows that, health promotion activities not only focus on media that can be applied by teenagers, but must also be accepted by parents or families. Based on data about the opinions of respondents regarding the delivery of information through booklets, it is known that most of the respondents give good response (Tables 3 and 4). Therefore, the delivery of information through booklets can be an appropriate method in order to increase family knowledge including knowledge about drug users.

The significant role of parental knowledge to protect adolescents against negative behavior is supported by the results of research conducted by Cutrín, et al., 2017 where highly support of parent might be only effective in reducing antisocial behavior in adolescents if the level of parental knowledge is increased (Cutrín, Gómez-Fraguela and Sobral, 2017). The results of other related studies also show that parental knowledge about adolescent behavior is associated with drinking behavior in adolescents, where a 
high level of parental knowledge has a significant relationship with low drinking behavior in adolescents aged 14-18 years (Mustanski et al., 2017). Based on a number of the results of these studies, it can be a suggestion for parents to have sufficient knowledge about narcotics and illegal drugs, the ways and dangers of their abuse and how to characterize both the physical, emotional and behavior of a person abusing substance abusers.

Health promotion activities given to parents and families about the characteristics of drug users by understanding the characteristics of drug users can be recommended to be done continuously and with an approach that promotes local wisdom such as aspects of the local language. Submitting information using language that easily understood will make it easier for the recipient of the message to understand the contents of the message delivered. A study of risk factors and protective factors related to the health of Native American Indians and Alaskan adolescents is known that among the factors that influence mental health and possibly protect adolescents from substance abuse that is the support of family, community and culture. Especially on cultural factors, tribal language is identified to protect adolescents from delinquent behavior. It prevents indirectly adolescents from risky behavior in the abuse of certain substances (Burnette and Figley, 2016).

The use of regional languages in the promotion of drug abuse prevention is a form of utilization of local cultural wisdom. The results of research on health promotion in communities with diverse cultural backgrounds might emerge some obstacles in the health promotion activities which causes the objectives achievement of activities not optimal. Therefore, this study recommends that program development and modification must be able to meet the needs of communities with diverse cultural backgrounds (Ruiz-Casares et al., 2017). The results of research conducted by Hadley et al (2016) recommend the use of culture-sensitive technology-based media as a means of health promotion in order

\section{as a means of health promotion in order}

to prevent the risky sexual behavior in African American adolescents (Hadley et al., 2016). Local language as a means of intra-ethnic communication, especially in its function as a method of delivering information, the choice of words used must have historical values, contain noble moral and cultural values such as through expressions and general proverbs besides it is well-known by their time so that the message conveyed can be well received (Darwis, 2011).

Thus, aspects of local cultural wisdom need to be applied in designing health promotion programs for adolescents and families, including knowledge about drugs. The use of various media both printed and electronic media in order to deliver health messages can affect one's knowledge (Mirzanie, Prawitasari and Widad, 2019). In relation to knowledge about drug abuse, most respondents said that they obtained this information through television. Thus, the application of regional languages in health promotion through television and other online media can be a consideration for the development of health promotion methods to increase public knowledge in the future.

\section{CONCLUSION}

Knowledge about the characteristics of drug users between respondents reading the local Bimanesse language booklet and respondents reading bahasa Indonesia booklets were not significantly different. However, the univariate test showed a higher than average score in the treatment group compared to the control group. Therefore, health promotion for families and adolescents in Bima district especially for the prevention of abuse of narcotics, psychotropic substances and other addictive substances, can be applied with media that uses the local Bimanesse language and bahasa Indonesia as the language of instruction in the delivery of information. It is recommended for further research on how to apply regional languages as an approach to health promotion through traditional arts 
activities such as traditional dances and songs.

\section{REFERENCES}

Antaranews (2015) 'BNN NTB: Pecandu narkoba 20 ribu orang', pp. 2-7.

Bertha, O. (2014) 'Minority ethnic adolescents' wellbeing: Child rearing practices and positive family influences', Health Education Journal, 73(3), pp. 324331.

Burnette, C. and Figley, C. (2016) 'Risk and Protective Factors Related to the Wellness of American Indian and Alaska Native Youth: A Systematic Review', International Public Health Journal, 8(2), p. 137.

Cutrín, O., Gómez-Fraguela, J. A. and Sobral, J. (2017) 'Two Faces of Parental Support: Risk and Protection for Antisocial Youth Depending on Parental Knowledge', Journal of Child and Family Studies. Springer US, 26(1), pp. 296-305. doi: 10.1007/s10826-016-0559-6.

Darwis, H. M. (2011) Nasib Bahasa Daerah di Era Globalisasi: Peluang Dan Tantangan. Makasar.

Hadley, W. et al. (2016) 'Work It Out Together: Preliminary Efficacy of a Parent and Adolescent DVD and Workbook Intervention on Adolescent Sexual and Substance Use Attitudes and Parenting Behaviors', AIDS and Behavior. Springer US, 20(9), pp. 1961-1972. doi: $10.1007 / \mathrm{s} 10461-016-1418-6$.

El Kazdouh, H. et al. (2018) 'Adolescents, parents and teachers' perceptions of risk and protective factors of substance use in Moroccan adolescents: a qualitative study', Substance abuse treatment, prevention, and policy. Substance Abuse Treatment, Prevention, and Policy, 13(1), p. 31. doi: 10.1186/s13011-018-0169-y.

Merga, M. K. and Hu, Q. M. (2016) 'Health education beyond the school gates: Use of school newsletters to communicate health messages to parents and their families', Australian Journal of Education, 60(1), pp. 73-85. doi: 10.1177/0004944115627567.
Mirzanie, H., Prawitasari, S. and Widad, S. (2019) 'Pengaruh Metode Promosi Kesehatan Terhadap Pengetahuan dan Sikap Kader tentang Deteksi Dini Kanker Leher Rahim', Jurnal Kesehatan Reproduksi, 6(1), p. 19. doi: $10.22146 / \mathrm{jkr} .42373$.

Mustanski, B. et al. (2017) 'Effects of Parental Monitoring and Knowledge on Substance Use and HIV Risk Behaviors Among Young Men Who have Sex with Men: Results from Three Studies', AIDS and Behavior. Springer US, 21(7), pp. 2046-2058. doi: 10.1007/s10461-017-1761-2.

Nasir, M. J., Khan, A. S. and Tabassum, I. (2015) 'Socio-Economic Profile of Drug Abusers Attending a Treatment Center in Peshawar, Pakistan', The Journal of Humanities and Social Sciences, 23(3), pp. 57-72.

Nurmaya, A. (2016) 'Penyalahgunaan napza di kalangan remaja (studi kasus pada 2 Siswa di MAN 2 Kota Bima)', Jurnal Psikologi Pendidikan \& Konseling, 2(1), pp. 26-32.

Pusat Data dan Informasi Kemeterian Kesehatan RI (2014) 'Gambaran umum penyalahgunaan narkoba di Indonesia', Buletin Jendela Data dan Informasi Kesehatan, pp. 115.

Ruiz-Casares, M. et al. (2017) 'Parenting for the promotion of adolescent mental health: a scoping review of programmes targeting ethnoculturally diverse families', Health and Social Care in the Community, 25(2), pp. 743-757. doi: $10.1111 /$ hsc. 12364 .

Rusmiati, D., Silitonga, T. Y. and Warendi, W. (2018) 'Effect of Health Promotion on Knowledge and Intention for Early Detection of Cervical Cancer in Commercial Sex Workers', Kesmas: National Public Health Journal, 13(2), pp. 70-74. doi: 10.21109/kesmas.v13i2.1919.

Schulte PhD, M. T. and Hser PhD, Y.-I. (2014) 'Substance Use and Associated Health Conditions throughout the Lifespan', Public Health Reviews, 35(2), pp. 1-27.

Scull, T. M., Kupersmidt, J. B. and 
132 Jurnal Promkes: The Indonesian Journal of Health promotion and Health Education Vol. 7 No. 2 Desember 2019 : 124 - 132, doi: 10.20473/jpk.V7.12.2019.124-132

Erausquin, J. T. (2014) 'The Impact of Media-Related Cognitions on Children's Substance Use Outcomes in the Context of Parental and Peer Substance Use', Journal of Youth and Adolescence, 43(5), pp. 717728. doi: 10.1007/s10964-0130012-8.

Solehati, T., Rahmat, A. and Eli Kosasih, C. (2019) 'Hubungan Media dengan Sikap dan Perilaku Triad Kesehatan Reproduksi Remaja', Jurnal Penelitian Komunikasi dan Opini Publik, 23(1), pp. 40-53.

SUARANTB.com (2016) 'Kasus narkoba di Bima terus naik', p. 1.
Unger, J. B., Ritt-olson, A. and Baezconde-garbanati, D. W. S. L. (2009) 'Parent - Child Acculturation Discrepancies as a Risk Factor for Substance Use among Hispanic Adolescents in Southern California', Journal Immigrant Minority Health, 11(3), pp. 149-157. doi: 10.1007/s10903007-9083-5.

Ungsianik, T. and Yuliati, T. (2017) 'Pola asuh orangtua berhubungan dengan perilaku seksual berisko pada remaja binaan rumah singgah', Jurnal Keperawatan Indonesia, 20(3), pp. 185-194. doi: $10.7454 / j k i . v 20 i 3.623$. 